\title{
STUDY OF PREVALENCE OF NON-ALCOHOLIC FATTY LIVER DISEASE AND ITS ASSOCIATION WITH TYPE 2 DIABETES MELLITUS IN A TERTIARY CARE HOSPITAL
}

\author{
Ramya Bhat $S^{1}$, Indumathi Shankaraiah ${ }^{2}$
}

${ }_{1}^{1}$ Assistant Professor, Department of Medicine, Subbaiah Medical College, Shivamogga, Karnataka, India.

${ }^{2}$ Assistant Professor, Department of Medicine, Subbaiah Medical College, Shivamogga, Karnataka, India.

\section{ABSTRACT}

\section{BACKGROUND}

Non-Alcoholic Fatty Liver Disease (NAFLD) is a distinct clinical entity and is one of the most common causes of chronic liver disease globally. Prevalence is estimated to be around 9-30\% in general Indian population, with a higher incidence in obese and diabetic patients.

\section{METHODS}

This is a prospective observational study where patients with Type 2 Diabetes were recruited. History was taken and physical examination was performed. Laboratory investigations such as fasting blood glucose, 2-hour post-prandial blood glucose, blood urea, serum creatinine, liver function tests, lipid profile, glycated haemoglobin were done. NAFLD was diagnosed with ultrasonography of the abdomen.

\section{RESULTS}

The study group $(n=100)$ was divided into a NAFLD group $(n=49)$ and a non-NAFLD group $(n=51)$. The prevalence of NAFLD was 49\%. The NAFLD subgroup had higher prevalence of obesity (measured by BMI), central obesity (measured by waist circumference and waist hip ratio), higher HbA1c, higher triglyceride levels and lower HDL levels. Binary logistic regression analysis showed a significant correlation with glycated $\mathrm{Hb}(\mathrm{p}=0.001)$, triglycerides $(\mathrm{p}=<0.001)$, obesity $(\mathrm{p}=<0.001)$ and the incidence of NAFLD.

\section{CONCLUSIONS}

Incidence of NAFLD is increasing in general population. But patients with type 2 diabetes mellitus have increased risk for development of NAFLD when compared to general population. This risk is further increased in people with obesity especially central obesity, which is a risk factor for insulin resistance. In our study, we found that patients with poor glycaemic control had increased incidence of NAFLD when compared to those with good glycaemic control. Also, dyslipidaemia especially hypertriglyceridemia increased the risk of NAFLD.

\section{KEY WORDS}

NAFLD, NASH, Hypertriglyceridemia, Obesity, Ultrasonography

HOW TO CITE THIS ARTICLE: Bhat RS, Shankaraiah I. Study of prevalence of non-alcoholic fatty liver disease and its association with type 2 diabetes mellitus in a tertiary care hospital. J. Evolution Med. Dent. Sci. 2019;8(23):1830-1833, DOI: $10.14260 /$ jemds/2019/402

\section{BACKGROUND}

In 1980, Ludwig and colleagues from the Mayo clinic coined the term Non-Alcoholic Steato Hepatitis (NASH) to describe a form of liver disease observed in middle-aged patients with abnormal liver biochemical test results and histologic evidence of alcoholic hepatitis but with no history of alcohol abuse.[1] NAFLD is a condition defined by excessive fat accumulation in the form of triglycerides (Steatosis) in the liver ( $>5 \%$ of hepatocytes histologically). A subgroup of NAFLD patients have liver cell injury and inflammation in addition to excessive fat (Steatohepatitis). The latter condition, designated NASH, is virtually indistinguishable histologically from alcoholic steatohepatitis (ASH).

'Financial or Other Competing Interest': None.

Submission 20-04-2019, Peer Review 24-05-2019,

Acceptance 01-06-2019, Published 10-06-2019.

Corresponding Author:

Dr. Indumathi,

\#S3, A-Block, Teaching Faculty Quarters,

Subbaiah Institute of Medical Sciences,

NH-13, Purlae, H. H. Road,

Shimoga-577222,

Karnataka, India

E-mail:drindu126@gmail.com

DOI: $10.14260 /$ jemds $/ 2019 / 402$
While the simple steatosis seen in NAFLD does not correlate with increased short-term morbidity or mortality, progression of this condition to that of NASH dramatically increases the risks of cirrhosis, liver failure, and hepatocellular carcinoma (HCC).[2]

It is now known that many patients with hitherto identified "cryptogenic" cirrhosis in fact have liver disease on the basis of NASH, with the resolution of the steatosis once patients become catabolic due to cirrhosis. [3] Epidemiological studies suggest that its prevalence is around $9 \%$ to $32 \%$ in the general population, but higher in individuals who are overweight or have obesity and diabetes.[4] Most cases of NAFLD are discovered in the fourth to sixth decades of life. In early clinical studies, the majority of patients with NAFLD were female; however, subsequent data have suggested that men may be affected as often as women and may be at greater risk for advanced forms of NAFLD, including NASH. The prevalence of NAFLD appears to vary by ethnicity. The reasons for racial and ethnic disparities in the prevalence of NAFLD is not known but may be related, at least in part, to racial differences in body fat distribution and the prevalence of the metabolic syndrome, which is greatest in people of Hispanic descent. Familial clustering of NAFLD reflects both genetic and environmental predisposition to the metabolic conditions associated with NAFLD.[1] 


\section{METHODS}

Patients with type 2 diabetes mellitus diagnosed by WHO criteria and admitted as in patients in S.D.M. medical college and hospital, Dharwad were selected for the study. The study was a prospective observational study, conducted between October 2012 to November 2013. Patients satisfying the inclusion criteria were enrolled in the study, after providing written informed consent. A thorough medical history and physical examination was performed for each patient, which included measurement of weight and height, BMI, waist/hip ratio. After an overnight fasting, serum samples were obtained from all the participating patients for liver function tests, serum lipid profile, fasting blood glucose (FBS), Glycated haemoglobin (HbA1c),

Overweight was defined as BMI between 25-29.99 $\mathrm{Kg} / \mathrm{mt} 2$. Obesity as BMI $>=30 \mathrm{~kg} / \mathrm{mt} 2$. Patients were considered centrally obese if the waist circumference was greater than $>80 \mathrm{~cm}$ in females and $>90 \mathrm{~cm}$ in males. Patients with one of the criteria: $\mathrm{LDL}-\mathrm{C}>=100 \mathrm{mg} / \mathrm{dl}$, total cholesterol $>200 \mathrm{mg} / \mathrm{dl}$, TAG $>=150 \mathrm{mg} / \mathrm{dl}$ or HDL-C $<40 \mathrm{mg} / \mathrm{dl}$ in males and $<50 \mathrm{mg} / \mathrm{dl}$ in females were considered to have dyslipidaemia.

All patients underwent abdominal ultrasonography by the radiologist for evidence of fatty liver disease. NAFLD was diagnosed based on USG findings (Diffuse increase in echogenicity as compare to that of spleen or renal cortex.).

\section{Statistical Analysis}

The data were analysed applying $\chi 2$-test, uni variate logistic regression analysis of significance, using SPSS software. Chisquare test and student $\mathrm{t}$ test is used. Data calculated in MS excel 2007, p value is given. Value less than 0.05 was taken as statistically significant.

To summarize in this study statistically significant relationship was found between incidence of NAFLD and with increase in weight, BMI, waist circumference, waist-hip ratio, FBS levels, PPBS level, HbA1c levels, triglycerides levels.

\section{RESULTS}

Gender distribution of study population. In this study female constituted to 57 patients and male to 43 patients.

Most patients who come to medical attention with NAFLD are identified as a result of incidentally discovered elevated liver enzymes (ALT, AST). ALT is generally higher than AST, and aminotransferases are only mildly (1.5-2 times the upper limit of normal) elevated. Recent studies have shown that many patients can have advanced fibrosis with NASH and even cirrhosis due to NASH with normal liver enzymes, indicating that the prevalence of the disease is likely to be even greater than was previously suspected..[5]

NASH is frequently seen in conjunction with other components of the metabolic syndrome (hypertension, diabetes mellitus, elevated lipids, and obesity), with NAFLD being considered the hepatic manifestation of this syndrome.[6,7] Insulin resistance is the underlying link between these various disorders and numerous studies have shown that virtually all patients with NASH have insulin resistance. ${ }^{[8,9,10]}$ Abnormal ferritin values are seen in $50 \%$ of patients with $\mathrm{NASH}$, and an elevated ferritin level may be a marker of insulin resistance in NASH.[5]

\begin{tabular}{|c|c|c|}
\hline Age & Frequency & Percent \\
\hline $31-40$ & 1 & 1.0 \\
\hline $41-50$ & 22 & 22.0 \\
\hline $51-60$ & 30 & 30.0 \\
\hline $61-70$ & 35 & 35.0 \\
\hline $71-80$ & 10 & 10.0 \\
\hline$>80$ & 2 & 2.0 \\
\hline Total & $\mathbf{1 0 0}$ & $\mathbf{1 0 0 . 0}$ \\
\hline
\end{tabular}

\section{Table 1. Age Distribution in Study Population}

In this study maximum no. of study subjects were in 6th decade followed by 5 th and 4 th decade.

\begin{tabular}{|c|c|c|}
\hline Duration of DM & Frequency & Percent \\
\hline$<5$ & 53 & 53.0 \\
\hline $5-10$ & 27 & 27.0 \\
\hline $10-20$ & 19 & 19.0 \\
\hline$>20$ & 1 & 1.0 \\
\hline Total & $\mathbf{1 0 0}$ & $\mathbf{1 0 0 . 0}$ \\
\hline Table 2. Duration of DM Distribution in Study Population \\
\hline $\begin{array}{r}\text { In this study 53 subjects had duration of diabetes less 5 yrs., } 27 \text { of them } \\
\text { had for 5 to 10 yrs. and 19 of them had for 10-20 yrs. }\end{array}$ \\
\hline
\end{tabular}

\begin{tabular}{|c|c|c|}
\hline BMI Class & Frequency & Percentage \\
\hline $18-24.99$ & 26 & 26.0 \\
\hline $25-29.99$ & 42 & 42.0 \\
\hline $30-34.99$ & 28 & 28.0 \\
\hline $35-39.99$ & 4 & 4.0 \\
\hline$>=40$ & 0 & 0 \\
\hline Total & 100 & 100.0 \\
\hline
\end{tabular}

In this study 42 study subjects were overweight, 28 of subjects had grade 1 obesity and 26 of them had normal BMI, 4 subjects had grade 2 obesity.

\begin{tabular}{|c|c|c|c|}
\hline Gender & NAFLD & NNAFLD & Total \\
\hline Male & 27 & 16 & 43 \\
\hline Female & 22 & 35 & 57 \\
\hline Total & $\mathbf{4 9}$ & $\mathbf{5 1}$ & $\mathbf{1 0 0}$ \\
\hline
\end{tabular}

Table 4. Gender Distribution of Fatty Liver Disease: $p$ Value- 0.017

In this study out of 43 males 27 had NAFLD and of 57 females 22 of them had NAFLD. P value is $<0.05$ so it is significant.

\begin{tabular}{|c|c|c|c|}
\hline BMI Class kg/mt2 & NAFLD & NNAFLD & Total \\
\hline $18.5-24.99$ & 6 & 20 & 26 \\
\hline $25-29.9$ & 17 & 25 & 42 \\
\hline $30-34.99$ & 22 & 6 & 28 \\
\hline $35-39.99$ & 4 & 0 & 4 \\
\hline Total & 49 & 51 & 100 \\
\hline Table 5. BMI Distribution of NAFLD: $\boldsymbol{p}$ Value- < 0.0001 \\
\hline P-value is <0.0001 hence data is statistically significant. Incidence of \\
NAFLD increases as BMI increases. \\
\hline
\end{tabular}

\begin{tabular}{|c|c|c|c|}
\hline FBS Class & NAFLD & NNAFLD & Total \\
\hline$<110 \mathrm{mg} / \mathrm{dl}$ & 6 & 12 & 18 \\
\hline $110-140 \mathrm{mg} / \mathrm{dl}$ & 11 & 12 & 23 \\
\hline $141-200 \mathrm{mg} / \mathrm{dl}$ & 10 & 14 & 24 \\
\hline$>200 \mathrm{mg} / \mathrm{dl}$ & 22 & 13 & 35 \\
\hline Total & $\mathbf{4 9}$ & $\mathbf{5 1}$ & $\mathbf{1 0 0}$ \\
\hline
\end{tabular}

Table 6. FBS in Distribution in NAFLD: $p$ Value- 0.009

In this group comparing range of FBS with the incidence of DM, $p$-value was 0.009 which is statistically significant. Hence in this study FBS at presentation had significant relation with the incidence of NAFLD

\begin{tabular}{|c|c|c|c|}
\hline PPBS Class & NAFLD & NNAFLD & Total \\
\hline$<140 \mathrm{mg} / \mathrm{dl}$ & 1 & 3 & 4 \\
\hline $141-200 \mathrm{mg} / \mathrm{dl}$ & 5 & 20 & 25 \\
\hline $201-300 \mathrm{mg} / \mathrm{dl}$ & 19 & 16 & 35 \\
\hline$>300 \mathrm{mg} / \mathrm{dl}$ & 24 & 12 & 36 \\
\hline Total & 49 & 51 & 100 \\
\hline \multicolumn{4}{|c|}{ Table 7. PPBS Distribution in NAFLD: $p$ Value- 0.003} \\
\hline \multicolumn{4}{|c|}{$\begin{array}{c}\text { p-value for PPBS at presentation and incidence of DM was } 0.003 \text { which } \\
\text { was statistically significant, implying that as PPBS increased the incidence } \\
\text { of NAFLD also increased. }\end{array}$} \\
\hline
\end{tabular}




\begin{tabular}{|c|c|c|c|}
\hline HbA1c Class & NAFLD & NNAFLD & Total \\
\hline$<7 \%$ & 4 & 20 & 24 \\
\hline $7.1-8 \%$ & 13 & 8 & 21 \\
\hline $8.1-9 \%$ & 5 & 7 & 12 \\
\hline $9.1-10 \%$ & 8 & 7 & 15 \\
\hline$>10 \mathrm{mg} \%$ & 19 & 9 & 28 \\
\hline Total & $\mathbf{4 9}$ & $\mathbf{5 1}$ & $\mathbf{1 0 0}$ \\
\hline \multicolumn{3}{|c|}{ Table 8. HbA1c Distribution in NAFLD: $\boldsymbol{p}$ Value- 0.003} \\
\hline In this study p-value between of HbA1c level and incidence of NAFLD is \\
0.003 which is statistically significant, i.e. as the HbA1c level increases, \\
incidence of NAFLD increases. \\
\hline
\end{tabular}

\begin{tabular}{|c|c|c|c|}
\hline Triglycerides & NAFLD & NNAFLD & Total \\
\hline$<150 \mathrm{mg} / \mathrm{dl}$ & 13 & 34 & 47 \\
\hline$>150 \mathrm{mg} / \mathrm{dl}$ & 36 & 17 & 53 \\
\hline Total & $\mathbf{4 9}$ & $\mathbf{5 1}$ & $\mathbf{1 0 0}$ \\
\hline
\end{tabular}

Table 9. Triglyceride Distribution in NAFLD: $p$ Value- $<0.0001$

In this study p-value between triglycerides and incidence of NAFLD is $<0.001$, which is statistically significant, i.e. there is significant increase in incidence of NAFLD as triglycerides level increase.

\begin{tabular}{|c|c|c|c|c|}
\hline Waist-Hip Ratio & NAFLD & NNAFLD & Total \\
\hline \multirow{2}{*}{ Male } & $<0.90$ & 7 & 8 & 15 \\
\cline { 2 - 5 } & $>0.90$ & 20 & 8 & 28 \\
\hline Total & & $\mathbf{2 7}$ & $\mathbf{1 6}$ & $\mathbf{4 3}$ \\
\hline \multirow{2}{*}{ Female } & $<0.85$ & 2 & 16 & 18 \\
\cline { 2 - 5 } & $>0.85$ & 20 & 19 & 39 \\
\hline Total & \multicolumn{5}{|c|}{ Table 10. Waist-Hip Ratio in NAFLD } \\
\hline \multicolumn{5}{|c|}{ Male -P value- 0.109, Female- P value- 0.0037 } \\
\hline \multicolumn{5}{|c|}{$\begin{array}{c}\text { In this study p-value between waist hip ratio and incidence of NAFLD in } \\
\text { males was 0.109 which is not statistically significant. Whereas in female } \\
\text { p-value is 0.0037 which suggests that there is statistically significant } \\
\text { relation between the two entities. }\end{array}$} \\
\hline
\end{tabular}

\section{DISCUSSION}

Incidence of NAFLD is increasing rapidly as its risk factors like obesity, diabetes mellitus, hypertension and dyslipidaemias.[10] Research to understand the pathogenesis of NAFLD is underway so that interventions to prevent or halt the progression of the disease can be invented. Weight loss and exercise are the only treatment available which can reduce the amount of steatosis and prevent its progression into fibrosis however these measure may not be effective once fibrosis is established.[11, 12] Measures like insulin sensitizers, antioxidants, lipid lowering agents are not fully effective.

The incidence of NAFLD among 100 patients with type 2 diabetes mellitus was found to be $49 \%$. This was comparable to a study done by Giovanniet al[13] which showed an incidence of $65 \%$. This finding was obtained by USG study, which can detect steatosis above 33\% hence if the patients were subjected to invasive liver biopsy then the actual incidence of NAFLD would be much higher. Gender based distribution of NAFLD showed that $27(62 \%)$ of 43 male patients, $22(43 \%)$ of 51 female patients had NAFLD. This was not comparable to $71 \%$ and $68 \%$ in male and female patients in a study done by Giovanni et al. In this study the difference in prevalence between male and female patient was found to be statistically significant as the p-value was 0.017 . Hence a male preponderance was found in our study.

In our study there was no significant variation observed in the incidence of NAFLD in different age groups ( $p$-value 0.503), this was comparable to a study done by AK Agharwal et al.[14] which showed no variation in different age group. But this not comparable to a study done by Giovanni et al.[13] which showed increased prevalence of NAFLD in patients more than 60 yrs. age group. There was a statistically significant increase in the incidence of NAFLD with increase in BMI ( $p$-vale <0.001) which was comparable to various studies like AK Agarwal et al. and Giorgio Bedogniet al.[15] Mean BMI in NAFLD group was $29.959 \mathrm{~kg} / \mathrm{mt} 2$, when compared to those without NAFLD was $26.02 \mathrm{~kg} / \mathrm{mt} 2$. The mean weight also significantly varied between two groups, with NAFLD mean weight was $70.88 \mathrm{~kg}$ whereas in those without NAFLD was $60.88 \mathrm{~kg}$.

A statistically significant relation was found with the incidence of NAFLD and waist hip ratio, waist circumference with a p-value of $<0.001$. This correlation was also found in other studies like AK Agharwal et al. (p-value 0.033) and Giorgio Bedogni et al ( $\mathrm{p}$ value 0.001).

In our study we found that values of FBS, PPBS and HbA1c correlated significantly with the incidence of NAFLD, with pvalues being, $0.009,<0.0001,0.001$ respectively. This suggest that with poor glycaemic control the risk of developing NAFLD proportionately increases. These findings was also seen in other studies like, Giorgio Bedogniet al ( $p$-value $0.007)$ and also in Giovanni et al ( $\mathrm{p}$-value $<0.0001)$. This finding was not observed in a study by AK Agharwal et al. ( $p$ value 0.178 ). There was no significant difference observed in values of liver function test like SGOT, SGPT and ALP in patients with NAFLD and without NAFLD. In study by AK Agharwal et al, Giorgio Bedogniet al, Giovanni et al, statistically significant correlation was found between SGOT, SGPT, ALP values and occurrence of NAFLD.

\section{Limitation of The Study}

Diagnosis of NAFLD was based on USG study of liver which identifies steatosis only when more than $33 \%$. Any steatosis less than could not be detected in this study. Also interobserver variation bias could not be eliminated.

Gold standard test for NAFLD diagnosis is liver biopsy and histopathology, which is not done in this study due to invasive nature of the study.

One of the criteria for diagnosis of metabolic syndrome is insulin resistance, which was not included in this study due to non-availability of the test in our institution.

\section{CONCLUSIONS}

Incidence of NAFLD is increasing in general population. But patients with type 2 diabetes mellitus have increased risk for development of NAFLD when compared to general population. This risk is further increased in people with obesity especially central obesity, which is a risk factor for insulin resistance. In our study, we found that patients with poor glycaemic control had increased incidence of NAFLD when compared to those with good glycaemic control. Also, dyslipidaemia especially hypertriglyceridemia increased the risk of NAFLD.

\section{REFERENCES}

[1] Reid AE. Non-alcoholic fatty liver disease. In: Feldman M, Frieddman LS, Brandt LJ, eds. Sleisenger and Fordtran's Gastrointestinal and Liver disease. 9th edn. Philadelphia: 2010: p. 1401-11.

[2] Dowman JK, Tomlinson JW, Newsome PN. Pathogenesis of non-alcoholic fatty liver disease. Q J Med 2010;103(2):71-83. 
[3] Caldwell SH, Argo CK. Non-alcoholic fatty liver disease and nutrition. In: Dooley JS, Lok ASF, Burroughs AK, et al. eds. Sherlock's Diseases of the liver and biliary system. 12th edn. West Sussex 2011: p. 546-62.

[4] Chawla YK, Taneja S. Non-Alcoholic fatty liver disease. In: Munjal YP, Sharma SK, eds. API Textbook of Medicine 9th edn. Mumbai: 2012: p. 885-7.

[5] Bacon BR. Genetic, Metabolic and infiltrative diseases affecting the liver. In: Fauci, Braunwald, Kasper, eds. Harrison's Principles of internal medicine. 18 ${ }^{\text {th }}$ edn. New York: McGraw-Hill Publications 2012: p. 2603-5.

[6] Day CP, James OF. Steatohepatitis: a tale of two 'hits'? Gastroenterology 1998;114(4):842-5.

[7] Jou J, Choi SS, Diehl AM. Mechanisms of disease progression in non-alcoholic fatty liver disease. Semin Liver Dis 2008;28(4):370-9.

[8] Roskams T, Yang SQ, Koteish A, et al. Oxidative stress and oval cell accumulation in mice and humans with alcoholic and non-alcoholic fatty liver disease. Am J Pathol 2003;163(4):1301-11.

[9] Mantzoros CS. The role of leptin in human obesity and disease: a review of current evidence. Ann Intern Med 1999;130(8):671-80.
[10] Younossi ZM. Review article: current management of non-alcoholic fatty liver disease and non-alcoholic steatohepatitis. Alimentary Pharmacology \& Therapeutics 2008;28(1):2-12.

[11] Huang XD, Fan Y, Zhang H, et al. Serum leptin and soluble leptin receptor in non-alcoholic fatty liver disease. World J Gastroenterol 2008;14(18):2888-93.

[12] Uygun A, Kadayifci A, Yesilova Z, et al. Serum leptin levels patients with non-alcoholic steatohepatitis. Am J Gastroenterol 2000;95(12):3584-9.

[13] Targher G, Bertolini L, Padovani R, et al. Prevalence of non-alcoholic fatty liver disease and its association with cardiovascular disease among type 2 diabetic patients. Diabetes Care 2007;30(5):1212-8.

[14] Agarwal AK, Jain V, Singla S, et al. Prevalence of nonalcoholic fatty liver disease and its correlation with coronary risk factors in patients with type 2 diabetes. J Assoc Physicians India 2011;59:351-4.

[15] Bedogni G, Miglioli L, Masutti F, et al. Prevalence of and risk factors for non-alcoholic fatty liver disease: the Dionysos Nutrition and Liver Study. Hepatology 2005;42(1):44-52. 